\title{
A Framework for Designing Nursing Knowledge Management Systems
}

\author{
Tzyh-Lih Hsia \\ Chinese Naval Academy, \\ Kaohsiung, Taiwan \\ boundy@cna.edu.tw
}

\author{
Li-Min Lin \\ Mei-Ho Institute of Technology, \\ Pingtung, Taiwan \\ x3213@mail.meiho.edu.tw
}

\author{
Jen-Her Wu and Hsien-Tang Tsai \\ National Sun Yat-Sen \\ University, Kaohsiung, Taiwan
}

jhwu@mis.nsysu.edu.tw htt@mail.nsysu.edu.tw

\begin{abstract}
The health care industry is increasingly becoming a knowledge-based community that depends critically on knowledge management (KM) activities to improve the quality of care. Utilizing knowledge management systems (KMS) to manage medical information and health care knowledge to support the full spectrum of knowledge needs in the nursing process has become an important issue for nursing professionals. Hence, the objective of this research is to propose a conceptual framework that integrates nursing process, KM activities, and enabling information technology (IT) for designing such a nursing KMS. The framework indicates the critical knowledge management activities in nursing process and the enabling IT based on the task/technology fit theory. With this framework, KMS developers can work with nursing professionals to easily identify the suitable IT associated with the nursing process when developing a nursing KMS.
\end{abstract}

Keywords: health care, e-health, knowledge management, knowledge management systems, nursing process

\section{Introduction}

Over the past decade, with the rapid advance in information technology (IT), the health care industry has increasingly embraced new IT and net-enabled applications in the search for opportunities for higher-quality care (Wu, Hung, Hisa, \& Tsai, in press). Recently, a growing interest in the electronic health (e-health) concept is causing significant changes in the healthcare environment (Lin \& Umoh, 2002). As health care industry moves into the e-health age, health care organizations are becoming knowledge-based communities connected to hospitals, clinics, pharma-

Material published as part of this journal, either on-line or in print, is copyrighted by the Informing Science Institute. Permission to make digital or paper copy of part or all of these works for personal or classroom use is granted without fee provided that the copies are not made or distributed for profit or commercial advantage AND that copies 1) bear this notice in full and 2) give the full citation on the first page. It is permissible to abstract these works so long as credit is given. To copy in all other cases or to republish or to post on a server or to redistribute to lists requires specific permission and payment of a fee. Contact Publisher@InformingScience.org to request redistribution permission. cies, and customers for sharing

knowledge, reducing costs, and improving the quality of care. Thus, the success of e-health depends critically on the collection, analysis and seamless exchange of clinical and medical information or knowledge within and across the above organizational boundaries (Bose, 2003). 
Consequently, as e-health has become the norm, the barriers to transparent and accessible information are dissolving. Medical information and clinical knowledge management issues are beginning to emerge. The key challenges in these issues are: (1) how to integrate several disparate and standalone information repositories into a knowledge-based repository to create a single version for healthcare professionals, and (2) how to effectively manage this disparate knowledge using available IT facilities.

Managing knowledge of medical professionals within health care organizations is critical to prosper in competitive e-health environments (O’Dell \& Grayson, 1998). Nurses are knowledgeintensive and primary professional in health care organizations. They are required to take new nursing knowledge and experience that can be acquired through various net-enabled applications or Internet. Nursing professionals are being asked to do more with less in such context. While their nursing care responsibilities have increased, the IT support of nursing practices appears to lag far behind. This lack of IT support for nursing professionals has become an issue of significant importance. E-health requires better access to IT applications to analyze hospital-wide nursing care information and knowledge in the nursing process. As IT capabilities are extended to support a knowledge-centric view rather than simply a data-centric view, nursing practices must begin to take advantage of these new capabilities. A well-designed IT-based knowledge management system (KMS) has become an ever more central force in improving the quality of care in competitive e-health environments.

There is a general consensus that IT-based technologies could be applied to the development of healthcare KMS (Heathfield \& Louw, 1999; Ryu, Ho, \& Han, 2003). For instance, Kerwin (2002) indicated the importance of the Internet and related technologies in improving healthcare quality and medical KM. Selsy, Eisenberg, Hersh, \& Buitendijk (2001) reported that the electronic portal (e-portal) enables hospitals to integrate the medical knowledge into clinical workflow. Bose (2003) argued that a well-designed healthcare KMS infrastructure should incorporate necessary healthcare processes, tools, and techniques. However, very little is actually known about how to effectively integrate the technologies, knowledge management activities and the enabling IT in facilitating nursing knowledge management practices. To address this problem, a comprehensive framework that guides the design of a nursing KMS is necessary.

Therefore, the objective of this research is to propose a conceptual framework, based on task/technology fit (Goodhue \& Thompson, 1995), for designing nursing KMS which attempts to integrate the relevant enabling IT into the nursing process that would support nursing knowledge creation, application, and management. The proposed framework would assist the healthcare organizations to identify the critical nursing KM activities associated with the enabling IT and to plan for the nursing KMS for the nursing process.

\section{Background}

\section{E-Health}

Delivering healthcare services to patients is a complex endeavor that depends highly on healthrelated information. One of the major impediments in hospital progress toward efficiency and cost-effectiveness is the difficulty in sharing information among health care organizations (Grimson, Grimson, \& Hasselbring, 2000). Over the past decade, the health care industry has increasingly tried to embrace new IT, such as telephony, computers and Internet associated technologies, as it searched for opportunities for higher-quality care (Lin \& Umoh, 2002). E-health care is currently evolving, which refers to the delivery of healthcare services involving the electronic transfer of health-related information using electronic-based technologies (Englebardt \& Nelson, 2002). The Healthcare Information and Management System Society (HIMSS) broadly defined e- 
health as IT-enabled healthcare system that improves the access, efficiency, effectiveness and quality of clinical and business processes utilized by healthcare organizations, practitioners, and patients in an effort to accomplish some combination of the following objectives: cut costs, increase revenues, streamline operations, improve patient satisfaction, and contribute to the enhancement of medical care.

In e-health environments, it has become apparent that healthcare delivery is increasingly information-intensive; that is, healthcare organizations use more information sources to support clinical activities and care delivery, rather than interacting physically with the document, service, or a confined person (Michael, Goran, \& Jean, 2001). In such an environment, a significant challenge is how to integrate several disparate, stand alone information repositories into a single logical repository to create a single version of true for all healthcare stakeholders.

As healthcare organizations are drowning in information overload, KM is believed to be the current savior of organizations (King, Marks, \& McCoy, 2002). Currently, IT allows for supporting a knowledge-centric view, e-health solutions must begin to take advantage of these new capabilities. The health care industry has increasingly tried to embrace the knowledge managementenabled technologies and applications to improve the access and transfer of e-health information and knowledge at all levels (physicians, nurses, therapists, diagnosticians, and pharmacists). The knowledge management-enabled healthcare system is becoming the new trend in e-health (Bose, 2003).

\section{Knowledge Management}

Data becomes information when it can be summarized and organized into logical patterns. Information becomes knowledge when it can be manipulated for actionable decision making. In a broad sense, knowledge management (KM) is a management paradigm that includes concerted, coordinated and deliberate efforts to manage the organizational knowledge through processes for identifying and leveraging it to enhance the organizations ability to compete. KM is purported to increase innovativeness and responsiveness. According to the study by Davenport \& Prusake (1998), most KM projects have one of three aims: (1) to make knowledge visible and show the role of knowledge in an organization, mainly through maps, handbook, and hypertext tools; (2) to develop a knowledge-intensive culture by encouraging and aggregating behaviors such as knowledge sharing and proactively seeking and offering knowledge; (3) to build a knowledge infrastructure: a web of connections among people given space, time, tools, and encouragement to interact and collaborate.

Knowledge management can be viewed as turning data into information and forming information into knowledge. It is largely regarded as a cyclic process involving various activities (Nonaka, 1991). The process can be subdivided, for example, into creating internal knowledge, acquiring external knowledge, storing knowledge in documents versus storing in routines, as well as updating the knowledge and sharing knowledge internally and externally (Alavi \& Leidner, 2001). In light of the extant literature (Gover \& Davenport, 2001; Nonaka, 1991), the KM process can be generically represented as four cyclic activities: knowledge creation, knowledge codification, knowledge transfer, and knowledge application as shown in Figure 1. Knowledge creation includes all activities involved in the acquisition and development of knowledge. Knowledge codification involves the conversion of knowledge into accessible and applicable content. Knowledge transfer includes the sharing of knowledge from its point of creation or codified to the point of use. Knowledge application includes retrieving and applying codified knowledge in support of actions, decisions, or problem-solving. Ideally, these activities do not represent a monolithic set of activities, but an interconnected and intertwined set of activities. 


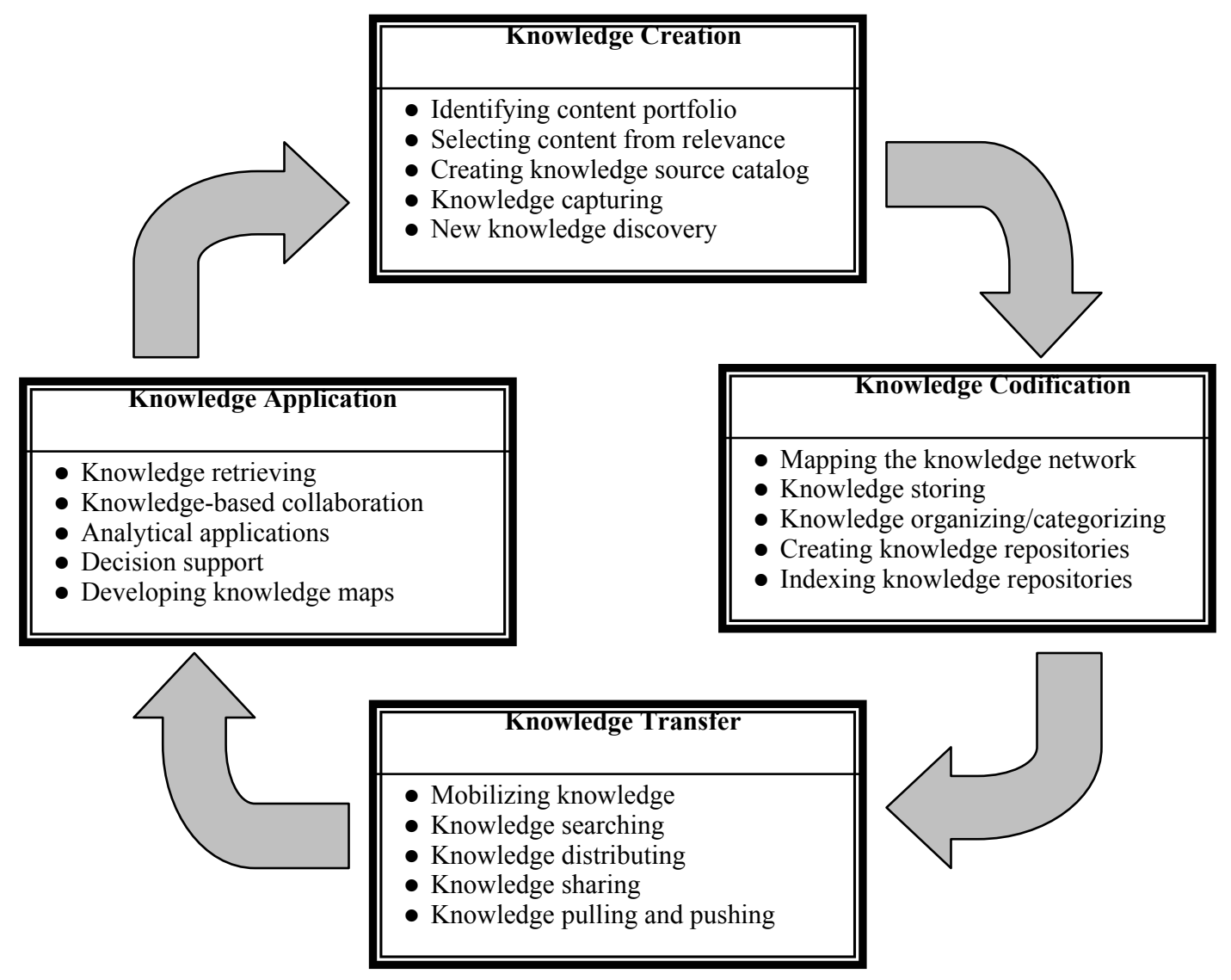

Figure 1: Knowledge Management Cycle

\section{Knowledge Management Systems}

Knowledge management systems refer to a class of information systems applied to manage organizational knowledge (Alavi \& Leidner, 2001). That is, they are IT-based systems developed to support and enhance the organizational processes of knowledge creation, storage, transfer, and application (Barnes, 2002). Many knowledge management initiatives rely on IT as an important enabler. Recently, progress in IT provides KM capabilities that were not possible before. Examples include finding an expert of recorded source of knowledge using online directories and searching databases; sharing knowledge and working together via Internet or Intranet; accessing to information on past projects; and learning about customers' needs by mining transaction data.

In light of the extant literature, three main KMS functions are included: (1) the codifying and sharing of internal best practices (O'Dell \& Grayson, 1998); (2) the creation of corporate knowledge directories (Ruggles, 1997), and (3) the creation of knowledge networks (Robey, Boudreau, $\&$ Rose, 2000). In fact, many new IT applications have been continually implemented to support organization knowledge management. Liao (2003) classified such KM technologies and applications into six categories: knowledge-based systems (KBS), data mining (DM), information and communication technology (ICT), artificial intelligence (AI) / expert systems (ES), database technology (DT), and modeling. 


\section{The Nursing Process}

In 1980, The American Nurses' Association defined nursing as "The diagnosis and treatment of human responses to actual or potential health problems." The practices (steps) of the nursing process including assessment, diagnosis, plan, implementation, and evaluation are cyclic, overlapping and interrelated.

- Step 1, assessment, is the most critical step and answers the questions: "What is happening (i.e., actual problem)?", or "What could happen (i.e., potential problem)?" This step involves collecting, organizing, and analyzing information/data about the patient. That is two parts: data collection and data analysis. In general, the data collection is a holistic approach and the methods of data collection can be observation, interview, and examination. The data types include subjective and objective data. The former can be "symptoms" that the patient describes; e.g. "I can't do anything for myself." The later can be "signs" that can be observed, measured, and verified; e.g., swollen joints.

- Step 2, diagnosis, is a statement that describes a specific human response to an actual or potential health problem that requires nursing intervention.

- Step 3, plan, provides consistent, continuous care that will meet the patient's unique needs, includes patient goals and nursing orders. The patient goals are directly related to the patient's problem as stated in the diagnosis, which describe the desired result of nursing care and the nursing order describes what the nurse will do to help the patient achieve the goals.

- Step 4, implementation, involves applying the skills needed to implement the nursing order. The major tasks include reassessing the patient, validating that the care plan is accurate, carrying out nurses' orders, documenting on patient's chart and so forth.

- Step 5, evaluation, compare the patient's current status with the stated patient goals and has three different operations or purposes: evaluation of the quality of the written care plan, evaluation of the client's progress, and evaluation of the status/currency of the care plan.

Nursing practices are increasingly being encoded in the form of nursing guidelines and protocols that drive health care service delivery. Nurses especially use the health care knowledge combined with their know-how and experience to deliver health care services. Today, this work can be enhanced by enabling technologies such as a KMS.

\section{Conceptual Framework for Designing Nursing KMS}

Nursing process involves several complex and knowledge-intensive practices that highly depend on nursing professional know-how and experience. Thus, whether nurses can utilize and manage their knowledge in nursing process effectively is vital to the quality of care. Technologies currently available allow for the development of e-health systems that can affect the entire professional experience for nurses. For instance, nurses can now electronically link to several or all information systems that influence their practice. These systems include electronic health records, medical knowledge bases, prescription ordering, and clinical decision support systems. The availability of theses e-health applications has introduced an opportunity for systems designers to develop integrated KMSs that can support the full spectrum of knowledge needs in nursing process. In fact, the use of knowledge-based IT to facilitate the practice of health care promises to substantially improve health care quality (Jadad, Haynes, Hunt, \& Browman, 2000).

A nursing KMS can be represented by a nursing service delivery model as well as the enabling IT to provide appropriate support for each KM activity in the nursing process. Given the wide array of information sources that can be integrated and accessible from the e-health environment, 
healthcare organizations should design and develop a nursing KMS that facilitate the integration and sharing of the collective experience and knowledge for nurses (Forgionne, Gangopadhyay, Klein, \& Eckhardt, 1999). A well-designed nursing KMS should provide nurses clinical information and knowledge where, when, and how they want it. Further, it can help eliminate the traditional separations of time and space, for example, physician office, rehabilitation, patient home, and chronic care office.

Sprague (1980) pointed out that the development of information systems should be informed by a well-designed framework. A KMS design framework should integrate business processes and the needed IT with the associated function to facilitate the KMS design (Alavi \& Leidner, 2001; Bose, 2003). It emphasizes the need to understand the organizational KM activities being supported, and signals a shift from technology-led to knowledge-led systems. To develop a successful nursing KMS, a conceptual framework is also required. A nursing KMS is an IT-based system developed to enhance the knowledge creation, codification, transfer, and application to support the nursing process. It can therefore be argued that the dimensions of nursing KMS design include both nursing process and KM technologies and are driven by the e-health environment, as depicted in Figure 2.

\section{E-health Environment}

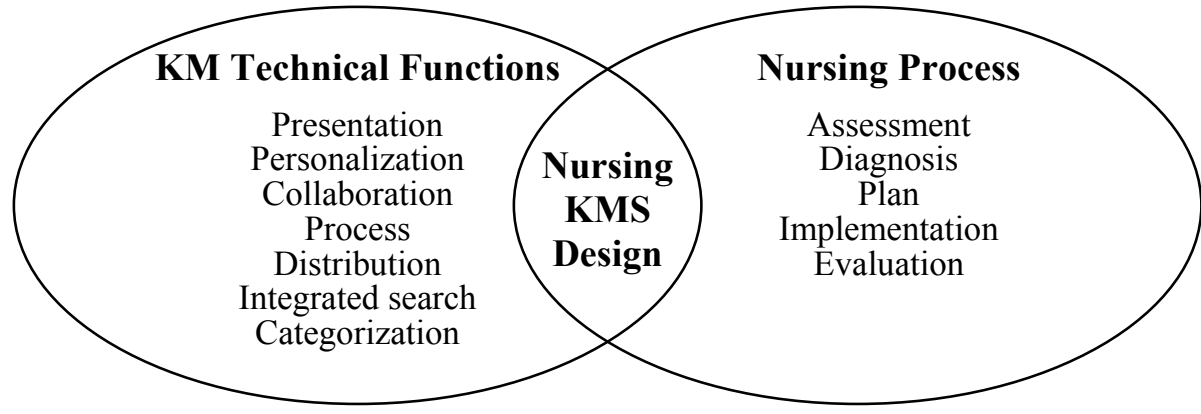

Figure 2: An integrated model of nursing KMS design

The model indicates the interplay between nursing practices and KM technologies in an e-health environment. The nursing process side consists of five basic practices: assessment, nursing diagnosis, plan, implementation and evaluation. It refers to the tacit and explicit nursing knowledge that is rooted in nursing process practices. To integrate $\mathrm{KM}$ activities into the nursing process and implement the nursing KM environment, healthcare organizations must provide and support various KM technical function categories through the deployment of available IT applications (Ruggles, 1997). According to Bose (2003), on the KM technical functions side, eight basic functions of KM technologies for nursing KMS are identified: presentation, personalization, collaboration, process, distribution, integrated search, and categorization functions. Table 1 summarizes the description of each KM technical function.

Table 1: Description of KM technical functions

\begin{tabular}{|l|l|}
\hline KM Technical Functions & \multicolumn{1}{c|}{ Description } \\
\hline Presentation & $\begin{array}{l}\text { It involves personalizing both access to and displaying the results of user } \\
\text { interactions with the system. }\end{array}$ \\
\hline Personalization & $\begin{array}{l}\text { It helps personalize content and services to deliver tailored content or in- } \\
\text { formation to user based on several user criteria or preference. }\end{array}$ \\
\hline
\end{tabular}




\begin{tabular}{|l|l|}
\hline Collaboration & $\begin{array}{l}\text { It is designed to connect people with people through communities of prac- } \\
\text { tices and to stimulate collaboration by integrating knowledge repositories } \\
\text { and collaboration applications. }\end{array}$ \\
\hline Process & $\begin{array}{l}\text { It allows users to participate in relevant business processes in the context } \\
\text { of their own roles. }\end{array}$ \\
\hline Publishing and distribution & $\begin{array}{l}\text { It provides the means and a platform for users to easily capture and dis- } \\
\text { tribute the particular kinds of knowledge they need to monitor without } \\
\text { requiring them to learn complex programming syntax. }\end{array}$ \\
\hline Integrated search & $\begin{array}{l}\text { It is designed to reduce the information overload and usefulness of search } \\
\text { results to the users. }\end{array}$ \\
\hline Category & It allows users to browse, create, and mange knowledge categories. \\
\hline Integration & $\begin{array}{l}\text { It ensures seamless and consistent navigation among knowledge sources } \\
\text { such that all individuals can use the organization's combined knowledge } \\
\text { and experience. }\end{array}$ \\
\hline
\end{tabular}

The aforementioned model indicated the underlying interconnectivity of the nursing practices and KM technical functions. These two factors coalesce into the overall nursing KMS functions. Task/technology fit theory (Goodhue \& Thompson, 1995) provides a theoretical basis for us to develop a framework that presents the interplay of the nursing practices, critical KM activities, suitable KM technical functions, and enabling IT facilities. Based on the review of nursing practices and KM technical functions, we match the critical KM activities, suitable KM technical functions, and enabling IT facilities with each practice of nursing process. Table 2 summarizes the matching results.

Table 2: A framework using enabling IT facilities to support nursing process

\begin{tabular}{|c|c|c|c|}
\hline Nursing Practices & $\begin{array}{c}\text { Critical KM } \\
\text { Activities }\end{array}$ & $\begin{array}{l}\text { KM Technical } \\
\text { Functions }\end{array}$ & Enabling IT \\
\hline Assessment & $\begin{array}{l}\text { Knowledge } \\
\text { application }\end{array}$ & $\begin{array}{l}\text { Presentation } \\
\text { Personalization } \\
\text { Integrated search }\end{array}$ & $\begin{array}{l}\text { Knowledge directories and } \\
\text { classifiers } \\
\text { Visualization } \\
\text { Rule-based personalization } \\
\text { Search engines } \\
\text { Online analytical processing } \\
\text { (OLAP) } \\
\text { FAQs }\end{array}$ \\
\hline Nursing Diagnosis & $\begin{array}{l}\text { Knowledge creation } \\
\text { Knowledge } \\
\text { application }\end{array}$ & $\begin{array}{l}\text { Integrated search } \\
\text { Collaboration } \\
\text { Process } \\
\text { Integration }\end{array}$ & $\begin{array}{l}\text { Intelligent agent } \\
\text { Knowledge-based systems } \\
\text { Expert systems } \\
\text { Case-based reasoning } \\
\text { Clinic decision support systems } \\
\text { (CDSS) } \\
\text { Data Mining } \\
\text { Discussion forums }\end{array}$ \\
\hline Plan & $\begin{array}{l}\text { Knowledge } \\
\text { codification }\end{array}$ & $\begin{array}{l}\text { Categorization } \\
\text { Publishing and } \\
\text { distribution }\end{array}$ & $\begin{array}{l}\text { Databases } \\
\text { Data warehouse } \\
\text { Knowledge repositories } \\
\text { Operational knowledge store } \\
\text { Electronic publishing }\end{array}$ \\
\hline Implementation & Knowledge transfer & Collaboration & $\begin{array}{l}\text { Intranet and Extranet } \\
\text { Workflow systems } \\
\text { Groupware }\end{array}$ \\
\hline
\end{tabular}




\begin{tabular}{|l|l|l|l|}
\hline Evaluation & $\begin{array}{l}\text { Knowledge } \\
\text { codification } \\
\text { Knowledge transfer }\end{array}$ & Integration & $\begin{array}{l}\text { Electronic portal (e-portal) } \\
\text { Decision support systems } \\
\text { (DSS) }\end{array}$ \\
& & $\begin{array}{l}\text { Group Decision support sys- } \\
\text { tems (GDSS) } \\
\text { Learning tools }\end{array}$ \\
\hline
\end{tabular}

Table 2 presents a set of KM technical functions of nursing KMS and illustrates a variety of enabling IT that may be drawn upon for supporting nursing practices in health care organizations. Of course, they are far from complete and exhaustive. The nursing KMS designers should decide on which practice(s) of the nursing process will focus on and link it to and employ enabling IT facilities as necessary. For example, if the intent is to provide nurses with the ability to search for detailed medical information to assist in assessment tasks, then a nursing KMS with detailed structured information and personalized healthcare records must be provided. Moreover, a nurse can also use knowledge directories (such as e-portal), search engines, and visualization (such as PACIS) to view other patient information sources.

\section{Concluding Remarks}

In this paper, we proposed an integrated model which emphasizes the interplay between nursing process and KM technical functions in the development of nursing KMS. Based on the task/technology fit theory, we further identify a set of KM technical functions that are necessary for a nursing KMS and a variety of enabling IT that can be used to support nursing practices and KM activities. The conceptual framework would immensely help healthcare organizations to identify their IT needs and to plan for the KM activities and technical infrastructure of the nursing KMS.

The contribution of this paper is two-fold. First, the framework provides a systematic guideline for KMS designers to adopt the enabling IT and the needed KM technical functions to support the activities in nursing process when designing a nursing KMS. With this framework, KMS designers can work with nursing professionals to easily identify suitable IT associated with the nursing process when developing a nursing KMS. Second, it can help the healthcare administrators and professionals to evaluate the potential of enabling IT and the opportunity it created to rethink or reengineer the nursing process and the associated activities based on the enabling IT capability.

The work is the beginning of a line of research focused on nursing informatics. It aims to develop a conceptual framework to identify the critical factors that involve in the development of nursing KMS. The proposed framework is far from complete and is a conceptual framework for action. Future research directions are abundant. For instance, in order to increase the applicability and usefulness of this framework, future research and development approach needs to be conducted to validate or enhance the proposed framework. Other issues may include integration with other information systems in healthcare environment to expand system capability.

\section{Acknowledgments}

The authors gratefully thank the anonymous Reviewers and Editor-in Chief for their valuable comments to enhance the quality of this paper. This research was supported by the National Science Council of Taiwan (Project No. NSC 93-2416-H-110-015)

\section{References}

Alavi, M. \& Leidner, D. E. (2001). Knowledge management and knowledge management systems: Conceptual foundations and research issues. MIS Quarterly, 25(1), 107-136. 
Barnes, S. (2002). Knowledge management systems: theory and practice. Thomson Learning Press.

Bose, R. (2003). Knowledge management-enabled health care management systems: Capabilities, infrastructure, and decision-support. Expert Systems with Applications, 24, 59-71

Davenport, T. H. \& Prusak, L. (1998). Working knowledge. Harvard Business School Press.

Englebardt, S. P. \& Nelson, R. (2002). Health care informatics: An interdisciplinary approach. Mosby Press.

Forgionne, G. A., Gangopadhyay, A., Klein, J. A., \& Eckhardt, R. (1999). Electronic commerce as an enabler of efficient healthcare decision making. Electronic markets, 9(2), 1-5.

Goodhue, D. L. \& Thompson, R. L. (1995). Task-technology fit and individual performance. MIS Quarterly, 19(2), 213-236.

Gover, V. \& Davenport, T. H. (2001). General perspectives on knowledge management: Fostering a research agenda. Journal of Management Information Systems, 18(1), 5-21.

Grimson, J., Grimson, W., \& Hasselbring, W. (2000). The system integration challenge in health care. Communications of ACM, 43(6), 49-55.

Heathfield, H., \& Louw, G. (1999). New challenge for clinical informatics: Knowledge management tools. Healthcare Informatics Journal, 5, 67-73.

Jadad, A. R., Haynes, R. B., Hunt, D., \& Browman, G. P. (2000). The Internet and evidence-based decision-making: A needed synergy for efficient knowledge management in health care. Canadian Medical Association Journal, 162(3), 362-365.

Kerwin, K. E. (2002). The role of the Internet in improving healthcare quality. Journal of Healthcare Management, 47(4), 225-236.

King, W. R., Jr. Marks, P. V., \& McCoy, S. (2002). The most important issues in knowledge management. Communications of the ACM, 45(9), 93-97.

Liao, S. H. (2003). Knowledge management technologies and applications - Literature review from 1995 to 2002. Expert Systems with Applications, 25, 59-71.

Lin, B. \& Umoh, D. (2002). E-healthcare: A vehicle of change. American Business Review, 20(2), 27-32.

Michael, J., Goran, MD., \& Jean, S. (2001). E-health: restructuring care delivery in the Internet age. Journal of Healthcare Information Management, 15(1), 3-12.

Nonaka, I. (1991). The knowledge creating company. Harvard Business Review, 69(6), 96-104.

O'Dell, C., \& Grayson, C. J. (1998). If only we knew what we know: Identification and transfer of internal best practice. California Management Review, 40(3), 154-174.

Robey, D., Boudreau, M. C., \& Rose, G. M. (2000). Information technology and organizational learning: A review and assessment of research. Accounting Management and Information Technologies, 10, 125155.

Ruggles, R. (1997). Knowledge management tools. Butterworth-Heinemann Press.

Ryu, S. Ho, S. H., \& Han, I. (2003). Knowledge sharing behavior of physicians in hospitals. Expert Systems with Applications, 25, 113-121.

Selsky, D. B., Eisenberg, F. P., Hersh, W., \& Buitendijk, H. J. (2001). Knowledge integration: Insight through the e-portal. Journal of Healthcare Information Management, 15(1), 13-24.

Sprague, R. H. (1980). A framework for the development decision support systems. MIS Quarterly, 4(4), 126.

Wu, J. H., Huang, A. S., Hisa, T. L, \& Tsaiand, H. T. (in press). Revolution or evolution? An analysis of ehealth innovation and impact using a hypercube model. International Journal of Electronic Healthcare, 2 . 


\section{Biographies}
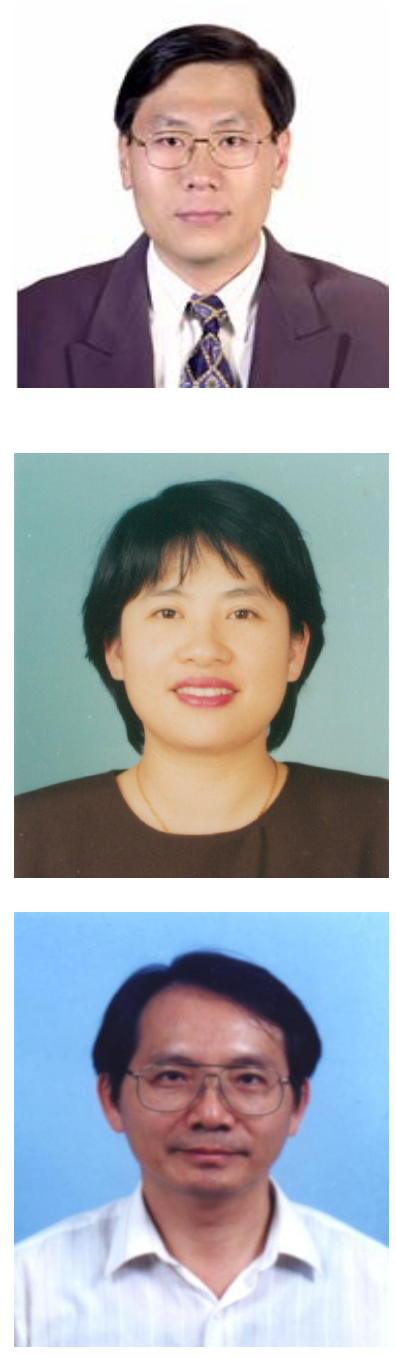

Tzyh-Lih Hsia is Assistant Professor of Department of Information Management, Chinese Naval Academy. After receiving a $\mathrm{PhD}$ from National Sun Yat-Sen University, he has been professionally associated with academic and research institutions. His articles have appeared in Journal of Organization Computing and Electronic Commerce, International Journal of Electronic Healthcare, and Electronic Commerce Research and Applications. His current research interests include electronic healthcare, electronic commerce and knowledge management.

Li-min Lin is Instructor at Mei-Ho Institute of Technology. She earned a MBA degree in Human Resource Management. Her articles have appeared in Computers in Human Behavior and Hospital Topics. Her current research interests include human resource management, electronic healthcare, and knowledge management.

Jen-Her Wu is Professor of Information Systems and Director of Institute of Health Care Management at National Sun Yat-Sen University. Prior to his doctoral study at the University of Kentucky, he received a BS degree in Industrial Design, earned an MS degree in Computer Science and worked as an engineer and manager in the manufacturing industry. He has published two books in SA\&D and more than 40 papers in professional journals such as Information \& Management, Computers in Human Behavior, Decision Support Systems, Journal of Organizational Computing and Electronic Commerce, and others. He also serves as an associate editor of Computers in Human Behavior and on the editorial board of Information \& Management. His current research interests include information systems development and management, human computer interaction, electronic commerce and innovation, and knowledge management.

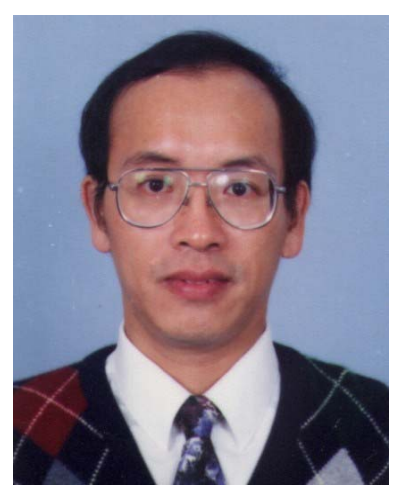

Hsien-Tang Tsai is a Professor of Management and the Dean of College of Management at National Sun Yat-Sen University, Kaohsiung, TAIWAN. His research interests are in the areas of management sciences, sustainable development, quality engineering, quantitative methods, etc. His work has appeared in Management Science, IIE Transaction, EJOR, JORS, Health Policy, etc. 